\title{
Special Issue Dedicated to IABEM 2011
}

\author{
Alberto Salvadori · Martin Schanz
}

Published online: 18 December 2012

(C) Springer-Verlag Berlin Heidelberg 2012

The 2011 Symposium of the International Association for Boundary Element Methods (IABEM) was held at the University of Brescia from September 5 to 8, 2011. About one hundred delegates, representing more than 20 different countries from all continents, attended the symposium, and 81 papers on engineering and mathematical aspects of the boundary element method (BEM) were presented. Topics included fracture mechanics, wave propagation, mathematical aspects, electromagnetics, fluid mechanics, fast methods, etc.

The symposium and the related cultural events were organized by the Department of Civil Engineering, Architecture, Land, Environment and of Mathematics (DICATAM) at the University of Brescia, by the Research Center of Seismology and Structural Dynamics (Cesia) and by the Scientific Association "Osvaldo De Donato" with the patronage of the Lombardy Region, the Province and the City of Brescia, as well as several more national scientific associations that cannot be listed for the sake of brevity.

In the week leading up to the international conference, from August 29 to September 2, a summer school was organized on "Large scale BEM computing." Internationally renowned lecturers, who attended the symposium thereafter, offered lectures to young researchers, who then took part in

\footnotetext{
A. Salvadori

DICATAM, Università di Brescia, via Branze 43,

25123 Brescia, Italy

M. Schanz ( $\varangle)$

Institute of Applied Mechanics, Graz University of Technology,

Technikerstr. 4, 8010 Graz, Austria

e-mail:m.schanz@tugraz.at
}

the symposium as well. The Summer School was attended by 25 students from all over the world.

A highlight of IABEM 2011 was the presentation of the Frank Rizzo Award for outstanding contributions in BEM. The 2011 Frank Rizzo Award was presented to Professor Jean-Claude Nédélec in recognition of his contributions to the field. Moreover, a minisymposium was organized to honor Professor S. Mukherjee, Cornell University, and Professor L. Gray, Oak Ridge National Laboratory, for their outstanding contributions to BEM in their long career before retirement. Fourteen lectures granted a large acknowledgment to such renown scientists.

A special session of the conference was organized in cooperation with Brescia Industrial Association (AIB). It dealt with "Industrial Applications of BEM", aiming at stimulating the interest of the local industry.

The organizers wish to express their special gratitude for the generous support the University of Brescia provided by funding the summer school, financially supporting the conference itself, and granting free access to many university facilities. The organizers also acknowledge the support provided by the Seminario Matematico Bresciano to the special session in honor of Prof. Gray and Prof. Mukherjee as well as the support of the Foundation Milziade Tirandi that provided sponsorship for accommodating young researchers during the symposium. The contributions of all these entities to the success of the symposium are gratefully acknowledged.

This issue of Computational Mechanics contains full length peer-reviewed versions of some of the contributions to IABEM 2011. We are honored and privileged to have served as guest editors of this special issue, and want to take this opportunity to thank the authors, and also the anonymous reviewers for their assistance in the successful completion of this task. On behalf of the IABEM Scientific 
Committee we want to thank Professor Peter Wriggers, Editor-in-Chief of Computational Mechanics, for hosting this special issue.

Brescia is now passing the baton to Santiago de Chile for the next IABEM symposium to be held in January 2013.
We look forward at such a stimulating event to further promote the development of BEM. 